原 著
|||||||||||||||||||||||||||||||||| $\mid$

\title{
ブラジルのサリトレ鉱床における風化カーボナタイト土䁃中 ウランのキャラクタリゼーション
}

\author{
金井 豊 $^{\dagger}$ \\ 産業技術総合研究所地質調查総合センター \\ 305-8567 茨城県つくば市東 1-1-1 \\ ${ }^{\dagger}$ y.kanai@aist.go.jp \\ 2015 年 8 月 20 日 受付 \\ 2015 年 11 月 9 日 受理
}

\begin{abstract}
ブラジルのサリトレ鉱床における風化カーボナタイト試料のウラン濃度は20-30 ppm 程度, ${ }^{234} \mathrm{U} /{ }^{238} \mathrm{U}$ 放射能比は約 1 で, マクロにはほほ放射平衡と見なせた。しかし, 放射能比が 0.72 程度で 容易に溶出，1程度で鉄などと溶出，1.02 前後で難溶性の各フラクションが推定された。溶出ウラ ンの放射能比が 1 よりも小さいのは, 強い風化作用で放射能比が低下した溶けやすいウランが一部 に残存し，それが溶出するためと考えられた。
\end{abstract}

Key Words: Brazil, Salitre mine, Carbonatite, Weathering, Uranium, Characterization

\section{1. はじめに}

カーボナタイトとは, 炭酸塩鉱物を主要構 成鉱物とするマントル起源の火成岩である。身 近な石灰岩は同じ炭酸塩鉱物から成るが堆積 岩であり, 火成炭酸塩岩であるカーボナタイ 卜とは産状の他にも炭素と酸素の同位体組成 が異なっている ${ }^{1,2)}$ 。カーボナタイトはニオブ $(\mathrm{Nb})$ ，希土類元素（REE）など多種類の鉱物 資源を含んでおり ${ }^{3)}$ ，資源として有用であるこ とはいうまでもないが, ウラン $(\mathrm{U})$ やトリウム （Th）などの放射性元素も比較的高濃度に含有 しており ${ }^{4)}$, 岩石学的, 鉱物学的, 化学的にも 興味深い。

カーボナタイト岩体は全世界で500カ所以上 も知られている。日本のような付加体からなる 島弧には馴染みの少ない岩体で, 世界の主要な 大陸地域の大きな構造線に沿って分布して，ア ルカリ複合岩体に伴うことが多い。これらは, アフリカ南部西海岸, アフリカ大地溝帯 (東. 西アフリカリフト), ブラジル南西部, ロシア
のコラ半島, カナダ東部などの地域に集中して おり，大陸分裂する際にマントルで形成された カーボナタイトマグマが大断層を通路として地 殼上部に到達し, カーボナタイト鉱床が形成さ れたものと考えられている5 。また，これらの カーボナタイト鉱床の形成時期は, 最も古いも のでは 25 億年を越えるものもあるが，その多 くは現在の各大陸へと分裂を開始した 2 億年前 以降に形成されている5)。

大きなカーボナタイト鉱床としては, 北米 カリフォルニア州のマウンテン・パス鉱床, 中 国四川省マオニューピン鉱床やブラジルのア ラシャ鉱床，カタロン鉱床などが知られてい る ${ }^{3,5)}$ 。このうちブラジルのカーボナタイト鉱 床については，資源探査・評価技術の向上を目 指してその産状・成因を地質学的に解明する プロジェクトを，ブラジル鉱産局と共同で地質 調查所（現産業技術総合研究所地質調查総合 センター）が1983年から 3 年間にわたって行っ た ${ }^{6,7)}$

本論文では，そのプロジェクトで得られた風 


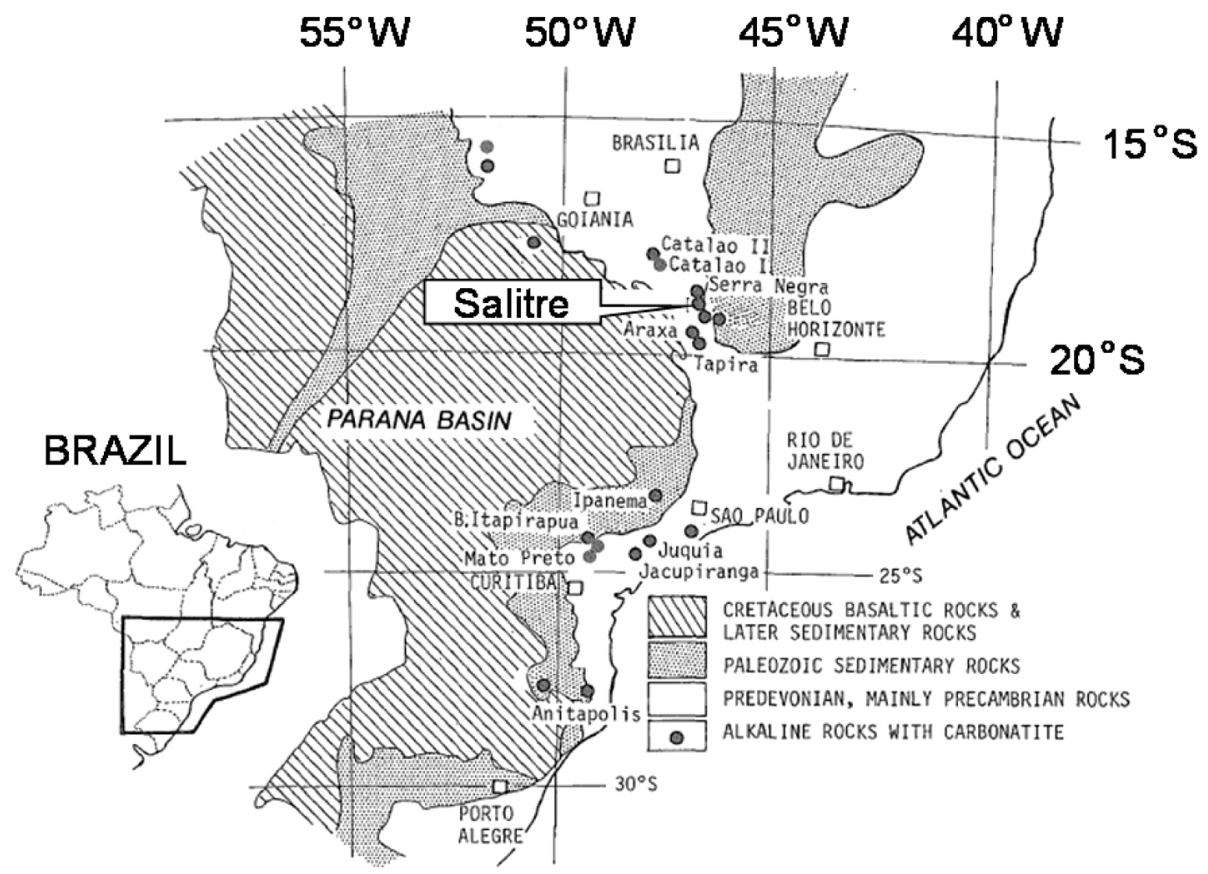

Fig. 1 Location map of the Salitre mine in Brazil with the outline of geology (modified from Hirano et al. $(1984)^{9)}$ ).

化カーボナタイト試料におけるUの地球化学に 注目し，ブラジルのサリトレ（Salitre）鉱床から 得た風化カーボナタイト試料におけるUの特徴を 明らかにするために，同位体組成や溶出特性な どについて検討したので，その結果を報告する。

\section{2. 試料}

ブラジルには, カタロン, アラシャ, サリ トレ, ジャクピランガなどのカーボナタイト 鉱床があるが ${ }^{8)}$, 主な試料は, サリトレ鉱床か ら採取した風化土壤である。サリトレ鉱床で は79-83 Maに先カンブリア時代の岩石にカー ボナタイト岩体が貫入したと考えられている が, 周辺のカタロン, アラシャ, ジャクピラン ガ鉱床では，貫入時期はそれぞれ $83 \mathrm{Ma}, 91 \mathrm{Ma}$, $130 \mathrm{Ma}$ と推定されている ${ }^{6)}$ 。サリトレ鉱床の位 置を周辺の地質 ${ }^{9)}$ と共にFig. 1 に示した。

サリトレ鉱床は数十から $100 \mathrm{~m}$ の厚みを持つ 風化したカーボナタイト鉱床である。ここで 採取した試料は, 水平方向約 $100 \mathrm{~m}$ の範囲にわ たって斜め下方に，表層の最高点から順次約
$1 \mathrm{~m}$ 深度ごとに $9 \mathrm{~m}$ まで採取した 10 試料である (Sal-1〜10)。これらの試料はめのう乳鉢で良 くすりつぶし，微粉末状にして分析に供した。

\section{3. 実験方法}

カーボナタイト試料のUの定量は, 試料粉末 $0.5 \mathrm{~g}$ をニッケルるつぼに取り, KOH融解一イオ ン交換法一固体蛍光法により行った ${ }^{4)}$ 。分析に は，特に記載されたもの以外は市販の特級試薬 を使用した。

$\mathrm{U}$ の放射能比 $\left({ }^{234} \mathrm{U} /{ }^{238} \mathrm{U}\right.$ 放射能比) は, アル ファ線スペクトロメトリーにより求めた。上 記イオン交換法で精製したU溶液の一定量を硫 酸アンモニア溶液に変えた後，0.7アンペア，2 時間通電してUをステンレス板に電着し，アル ファ線スペクトロメトリー用の線源とした ${ }^{10)}$ 。 表面障壁型シリコン半導体検出器（SSB）を内 蔵したCanberra社製の $7400 \mathrm{~A}$ 真空チャンバー の中に線源をセットし, マルチチャンネルアナ ライザーMCA S-85で計測して，得られたアル ファ線スペクトルにおける ${ }^{234} \mathrm{U}$ と ${ }^{238} \mathrm{U}$ のピーク 
面積比から放射能比を求めた。

また，Uの存在形態を明らかにするための抽 出実験では，鉱床域の平均的試料として Sal-6 を選び, 粉末試料 $0.5 \mathrm{~g}$ と $1 \mathrm{M}$ 酢酸アンモニウム 溶液, $0.1 \mathrm{M}$ 塩酸溶液, $1 \mathrm{M}$ 塩酸ヒドロキシルア ミン溶液, $1 \mathrm{M}$ シュウ酸溶液, $30 \%$ 過酸化水素 水，1 M 炭酸ナトリウム溶液など $30 \mathrm{~mL}$ を $50 \mathrm{~mL}$ 共栓付き試験管にとり，室温（R.T.）もしくは 加温して反応させ， ろ過後の溶出液ならびに残 さのU量と ${ }^{234} U /{ }^{238} U$ 放射能比を調べた。

\section{4. 結果と考察}

\section{$4 \cdot 1$ 化学組成とウランの濃度分布}

一般に風化カーボナタイト土壤は $\mathrm{Nb}$ や $\mathrm{Ta}$ どを大量に含有するが，サリトレ鉱山の試料 は比較的 $\mathrm{Nb}$ 含有量が少なく, Tiが主要な鉱物 資源となっている ${ }^{11)}$ 。採取した試料におけるU 濃度を，他の化学組成 ${ }^{6,12)}$ と共にTable 1 に示 した。 $\mathrm{TiO}_{2}$ は $17-26 \%, \mathrm{Fe}_{2} \mathrm{O}_{3}$ は32-43\%もあっ て，この両者でほぼ半分以上を占めている。U 濃度は 20-30 ppm 程度であり, ブラジルの他の
カーボナタイト鉱床であるアラシャ鉱床やカ タロン鉱床でのU濃度と比較すると低めである が, 通常の土壤や平均地殼存在度と比べると, 高濃度である4)

当地域では熱帯気候のためにラテライト化 がかなり進んで風化している。未風化の試料 が採取困難なために単純な比較はできないが, 他地域の岩石, 例えばアルカリ変質岩のU濃 度 0-6 ppm と比較すると数倍の濃縮となってい る。風化に伴うUなどの元素の濃縮は, 中国の ボーキサイト鉱床などでも観測されている ${ }^{13)}$ 一方, 鉱床域の深度方向に対するU濃度の顕著 な変化は認められなかった。

\section{$4 \cdot 2$ 風化カーボナタイト試料における ${ }^{234} \mathrm{U} /{ }^{238} \mathrm{U}$ 放射能比}

風化カーボナタイト土壤におけるUの特徵を 明らかにするために，サリトレ鉱床試料に扔け るUの放射能比 $\left({ }^{234} \mathrm{U} /{ }^{238} \mathrm{U}\right)$ を調べ，その結果 をTable 2 に示した。それによると、これらの 試料における ${ }^{234} \mathrm{U} /{ }^{238} \mathrm{U}$ 放射能比は，ほとんどの

Table 1 Chemical composition of weathered carbonatite samples taken from the Salitre mine, Brazil

\begin{tabular}{|c|c|c|c|c|c|c|c|c|c|c|c|}
\hline \multirow{2}{*}{\multicolumn{2}{|c|}{$\begin{array}{c}\text { Sample } \\
\text { Depth } / \mathrm{m}\end{array}$}} & Sal-1 & Sal-2 & Sal-3 & Sal-4 & Sal-5 & Sal-6 & Sal-7 & Sal-8 & Sal-9 & Sal-10 \\
\hline & & \multicolumn{2}{|c|}{ Lateritized soil } & \multicolumn{8}{|c|}{ P \& Ti ore body } \\
\hline \multicolumn{2}{|c|}{ Component } & Surface & 1 & 2 & 3 & 4 & 5 & 6 & 7 & 8 & 9 \\
\hline $\mathrm{SiO}_{2}$ & $(\%)^{*}$ & 6.24 & 6.68 & 6.10 & 4.76 & 10.76 & 11.09 & 7.15 & 6.78 & 8.76 & 6.01 \\
\hline $\mathrm{TiO}_{2}$ & $(\%)^{\star}$ & 23.15 & 23.45 & 23.06 & 17.04 & 20.57 & 21.11 & 25.58 & 25.71 & 24.47 & 24.83 \\
\hline $\mathrm{Al}_{2} \mathrm{O}_{3}$ & $(\%)^{*}$ & 12.11 & 11.85 & 11.96 & 10.05 & 11.28 & 11.51 & 7.92 & 7.56 & 8.66 & 11.00 \\
\hline $\mathrm{Fe}_{2} \mathrm{O}_{3}$ & $(\%)^{*}$ & 40.08 & 39.23 & 40.22 & 31.51 & 39.21 & 40.14 & 41.06 & 42.54 & 39.40 & 39.94 \\
\hline $\mathrm{MnO}$ & $(\%)^{*}$ & 0.27 & 0.24 & 0.28 & 0.20 & 0.24 & 0.25 & 0.32 & 0.34 & 0.40 & 0.26 \\
\hline $\mathrm{MgO}$ & $(\%)^{*}$ & 0.86 & 0.81 & 0.89 & 0.60 & 0.95 & 0.97 & 1.23 & 1.24 & 0.86 & 0.85 \\
\hline $\mathrm{CaO}$ & $(\%)^{\star}$ & 2.91 & 2.94 & 2.92 & 2.15 & 2.61 & 2.67 & 3.17 & 3.21 & 3.04 & 3.10 \\
\hline $\mathrm{Na}_{2} \mathrm{O}$ & $(\%)^{*}$ & 0.27 & 0.27 & 0.27 & 0.27 & 0.27 & 0.26 & 0.26 & 0.27 & 0.26 & 0.27 \\
\hline $\mathrm{K}_{2} \mathrm{O}$ & $(\%)^{*}$ & 0.05 & 0.05 & 0.05 & 0.05 & 0.05 & 0.05 & 0.05 & 0.05 & 0.05 & 0.05 \\
\hline $\mathrm{P}_{2} \mathrm{O}_{5}$ & $(\%)^{*}$ & 0.69 & 0.70 & 0.57 & 0.57 & 1.09 & 1.12 & 0.81 & 0.80 & 1.26 & 0.75 \\
\hline LOI & $(\%)^{*}$ & 9.22 & 9.44 & 9.68 & 9.68 & 8.60 & 7.79 & 6.48 & 6.21 & 7.84 & 8.56 \\
\hline $\mathrm{BaO}$ & $(\%)^{*}$ & $018-2-18$ & 0.19 & 0.15 & 0.1 & 0.33 & 0.34 & 0.3 & 0.35 & 0.66 & 0.19 \\
\hline $\mathrm{SrO}$ & $(\%)^{*}$ & 0.05 & 0.06 & 0.05 & 0.05 & 0.14 & 0.15 & 0.09 & 0.07 & 0.10 & 0.06 \\
\hline $\mathrm{ZrO}_{2}$ & $(\%)^{*}$ & 0.15 & 0.15 & 0.12 & 0.12 & 0.13 & 0.13 & 0.13 & 0.13 & 0.16 & 0.15 \\
\hline $\mathrm{Nb}_{2} \mathrm{O}_{5}$ & $(\%)^{\star *}$ & 0.00 & 0.08 & 0.00 & 0.00 & 0.10 & 0.00 & 0.00 & 0.00 & 0.00 & 0.00 \\
\hline $\mathrm{Ta}_{2} \mathrm{O}_{5}$ & $(\%)^{\star *}$ & 0.00 & 0.00 & 0.00 & 0.00 & 0.00 & 0.00 & 0.00 & 0.00 & 0.00 & 0.00 \\
\hline$U$ & $(\mathrm{ppm})^{\star \star \star}$ & 23.9 & 24.9 & 24.8 & 23.8 & 23.2 & 29.3 & 28.3 & 29.6 & 21.7 & 26.3 \\
\hline
\end{tabular}


Table $2{ }^{234} \mathrm{U} /{ }^{238} \mathrm{U}$ activity ratios of weathered carbonatite samples taken from the Salitre mine, Brazil

\begin{tabular}{ccccc}
\hline No. & Sample & Comment & $\begin{array}{c}U \text { content } \\
(\mathrm{ppm})\end{array}$ & $\begin{array}{c}{ }^{234} \mathrm{U} /{ }^{238} \mathrm{U} \\
\text { activity ratio }\end{array}$ \\
\hline 1 & Sal-01 & lateritized soil & 23.9 & $1.02 \pm 0.02$ \\
2 & Sal-02 & lateritized soil & 24.9 & $1.00 \pm 0.02$ \\
3 & Sal-"03 & P\&Ti ore body & 24.8 & $0.99 \pm 0.02$ \\
4 & Sal-04 & P\&Ti ore body & 23.8 & $1.01 \pm 0.02$ \\
5 & Sal-"05 & P\&Ti ore body & 23.2 & $1.02 \pm 0.02$ \\
6 & Sal-06 & P\&Ti ore body & 29.3 & $0.99 \pm 0.01$ \\
7 & Sal-"07 & P\&Ti ore body & 28.3 & $1.00 \pm 0.02$ \\
8 & Sal-08 & P\&Ti ore body & 29.6 & $1.03 \pm 0.02$ \\
9 & Sal-"09 & P\&Ti ore body & 21.7 & $1.00 \pm 0.02$ \\
10 & Sal-"10 & P\&Ti ore body & 26.3 & $0.99 \pm 0.02$ \\
\hline
\end{tabular}

試料で誤差の範囲で 1 に等しかった。

Uは酸化的環境では移動しやすいU（VI）と なるため，風化作用などによって酸化されると Uの移動が容易に起こる。また, U系列の親核 種 ${ }^{238} \mathrm{U}$ と 3 壊変後の娘核種 ${ }^{234} \mathrm{U}$ との間では, ア ルファ放射壊変に伴う反跳効果で結晶格子にお ける状態が異なり，親核種 ${ }^{238} \mathrm{U}$ に比べて娘核種 ${ }^{234} \mathrm{U}$ は移動しやすくなるので ${ }^{14,15)}$, その後の両 者の溶出挙動が異なる。このため, 古い岩石や 火成岩では ${ }^{234} \mathrm{U} /{ }^{238} \mathrm{U}$ 放射能比が 1 となることが 多いが, 酸化的な堆積物などでは娘核種 ${ }^{234} \mathrm{U}$ の 溶脱や濃集現象によって ${ }^{234} \mathrm{U} /{ }^{238} \mathrm{U}$ 放射能比が 1 から大きく外れることが多い。しかし，本研究 のほとんどの試料で, ${ }^{234} \mathrm{U} /{ }^{238} \mathrm{U}$ 放射能比は誤差 の範囲で1に等しいという結果になった。この 理由として, 現在も地表で風化作用を受けてい るにもかかわらず, マクロ的にはUの系外への 移動が行われず（何かにトラップされて閉鎖系 に近い形）保持されていた可能性や, 過去に移 動して非平衡となった後にかなり時間が経過し て ${ }^{234} \mathrm{U}$ の半減期 $0.25 \mathrm{Ma}$ の数倍以上 $)$, 再度平 衡状態に達している可能性などが考えられる。

このような結果が, 他の鉱床においても同 様であるかを確認するために, カタロン鉱床や アラシャ鉱床などの幾つかの試料について検討 したところ，多くの試料において ${ }^{234} \mathrm{U} /{ }^{238} \mathrm{U}$ 放射 能比が1に近いという結果であった（Table 3)。 しかし, カタロン鉱床のUの濃集部の試料や アラシャ鉱床のバライト含有試料では ${ }^{234} \mathrm{U} /{ }^{238} \mathrm{U}$
Table $3{ }^{234} \mathrm{U}^{238} \mathrm{U}$ activity ratios of other weathered carbonatite samples taken in this study in Brazil

\begin{tabular}{cclcc}
\hline No. & Sample & Comments & $\begin{array}{c}\text { U content } \\
(\mathrm{ppm})\end{array}$ & $\begin{array}{c}{ }^{234} \mathrm{U} /^{238} \mathrm{U} \\
\text { Activity ratio }\end{array}$ \\
\hline 1 & Catalao -03 & & 32.2 & $0.99 \pm 0.02$ \\
2 & Catalao -04 & a little siliceous & 363 & $0.99 \pm 0.01$ \\
3 & Catalao -05 & & 168 & $1.04 \pm 0.01$ \\
4 & Catalao -06 & abundant in P & 417 & $1.00 \pm 0.01$ \\
5 & Catalao -07 & ore body & 620 & $1.00 \pm 0.01$ \\
6 & Catalao $-07 a$ abundant in U\&Th & 1224 & $0.89 \pm 0.01$ \\
7 & Catalao -08 & ore body & 132 & $1.13 \pm 0.01$ \\
8 & Catalao -09 & lateritization & 101 & $1.00 \pm 0.02$ \\
9 & Catalao -10 & siliceous & 10.4 & $0.97 \pm 0.04$ \\
10 & Catalao -11 & abundant in REE & 462 & $0.94 \pm 0.01$ \\
11 & Araxa -01 & ore body & 33.1 & $1.04 \pm 0.02$ \\
12 & Araxa -02 & ore body & 53.3 & $1.00 \pm 0.02$ \\
13 & Araxa -03 & barite & 15.7 & $0.88 \pm 0.04$ \\
14 & Araxa -04 & ore body & 200 & $0.95 \pm 0.02$ \\
15 & Araxa -05 & lateritized soil & 83.4 & $0.95 \pm 0.02$ \\
16 & Araxa -06 & lateritized soil & 20.9 & $0.97 \pm 0.02$ \\
32 & Jacupiranga- & alkali altered rock & 6.17 & $1.03 \pm 0.04$ \\
\hline & 09 & & \\
\hline
\end{tabular}

放射能比が1から大きく外れていた。これら の鉱床の試料は, 露天掘りされている高さ $5 \mathrm{~m}$ おきの各段からおおむね採取されているが, ${ }^{234} \mathrm{U}{ }^{238} \mathrm{U}$ 放射能比が 1 から外れた部分では，お そらく移動性の高いU核種の溶脱（放射能 比 $<1$ ) や移動したU核種の取り込み（放射能 比>1）などが起きていた可能性が推定される。

\section{$4 \cdot 3$ 化学抽出によるUの溶出}

Uの存在形態をさらに詳細に検討するため, サリトレ鉱床の試料（Sal-6）に対して抽出実 験を行い, 溶出するU量とその ${ }^{234} \mathrm{U}^{238} \mathrm{U}$ 放射能 比を調べ, その結果を Table 4に示した。

抽出条件は様々であるが, 溶出したUの割合 は, $\mathrm{H}_{2} \mathrm{O}_{2}$ 水によるほとんど溶出しないレベル

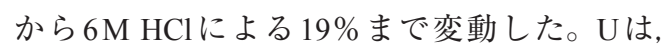
単独で存在するのではなく何らかの鉱物と共に 共存している可能性がある。特に実験対象試料 は $\mathrm{Fe}_{2} \mathrm{O}_{3}$ を $40 \%$ 程度も含有しているので（Table 1参照), 鉄含有鉱物の影響が大きいと考えら れる。そこで, 幾つかの試料について抽出液 の分析を行いFeとの関係を調べたところ， Fig. 2(a)のように実験デー夕全体での相関係数は 0.73 で, $98 \%$ の信頼度で相関があると判断され 
Table $4 \quad \mathrm{U}$ amounts and ${ }^{234} \mathrm{U} /{ }^{238} \mathrm{U}$ activity ratios leached from weathered carbonatite sample (Sal-6) by various chemical reagents

\begin{tabular}{|c|c|c|c|c|c|}
\hline \multirow{2}{*}{ No. } & \multicolumn{2}{|c|}{ Leaching conditions } & \multirow{2}{*}{ Soluble U (\%) } & \multicolumn{2}{|c|}{${ }^{234} \mathrm{U} /{ }^{238} \mathrm{U}$ activity ratio } \\
\hline & Reagent & Temperature (duration) & & Soluble U & Residual U \\
\hline 1 & $30 \% \mathrm{H}_{2} \mathrm{O}_{2}$ & R.T. $(13 \mathrm{~d})$ & $<0.1$ & & $1.04 \pm 0.01$ \\
\hline $1 a$ & $30 \% \mathrm{H}_{2} \mathrm{O}_{2}$ & $75^{\circ} \mathrm{C}(1 \mathrm{~d})+$ R.T. $(40 \mathrm{~d})$ & 0.1 & & \\
\hline 2 & $\mathrm{AcONH}_{4}(\mathrm{pH} 7)$ & R.T. $(13 d)$ & 0.2 & & $1.00 \pm 0.01$ \\
\hline 3 & $1 \mathrm{M} \mathrm{NH}_{2} \mathrm{OH} \cdot \mathrm{HCl}$ & R.T. $(13 \mathrm{~d})$ & 1.8 & $0.73 \pm 0.05$ & $1.04 \pm 0.02$ \\
\hline 4 & $1 \mathrm{M} \mathrm{NH}_{2} \mathrm{OH} \cdot \mathrm{HCl}+25 \% \mathrm{AcOH}$ & R.T. $(13 \mathrm{~d})$ & 6.5 & $0.72 \pm 0.03$ & $1.02 \pm 0.01$ \\
\hline $4 a$ & $1 \mathrm{M} \mathrm{NH}_{2} \mathrm{OH} \cdot \mathrm{HCl}+25 \% \mathrm{AcOH}$ & $75^{\circ} \mathrm{C}(1 \mathrm{~d})+$ R.T. $(40 \mathrm{~d})$ & 13.7 & $0.86 \pm 0.02$ & \\
\hline 5 & $1 \mathrm{M} \mathrm{Na}_{2} \mathrm{CO}_{3}$ & R.T. $(12$ d) & 6.1 & $0.71 \pm 0.03$ & $0.99 \pm 0.02$ \\
\hline $5 a$ & $1 \mathrm{M} \mathrm{Na}_{2} \mathrm{CO}_{3}$ & $75^{\circ} \mathrm{C}(1 \mathrm{~d})+$ R.T. $(40 \mathrm{~d})$ & 5.0 & $0.73 \pm 0.02$ & \\
\hline 6 & $1 \mathrm{M}$ Tartaric acid & $75^{\circ} \mathrm{C}(1 \mathrm{~d})+$ R.T. $(40 \mathrm{~d})$ & 7.2 & $0.81 \pm 0.02$ & \\
\hline 7 & $0.1 \mathrm{M} \mathrm{HCl}$ & R.T. $(13 \mathrm{~d})$ & 6.1 & $0.76 \pm 0.03$ & $1.04 \pm 0.01$ \\
\hline $7 a$ & $0.1 \mathrm{M} \mathrm{HCl}$ & $75^{\circ} \mathrm{C}(1 \mathrm{~d})+$ R.T. $(40 \mathrm{~d})$ & 9.7 & $0.72 \pm 0.02$ & \\
\hline 8 & $1 \mathrm{M} \mathrm{HCl}$ & R.T. $(15 \mathrm{~d})$ & 9.7 & $0.80 \pm 0.02$ & \\
\hline 9 & $6 \mathrm{M} \mathrm{HCl}$ & R.T. $(15 \mathrm{~d})$ & 18.8 & $0.90 \pm 0.02$ & \\
\hline 10 & $1 \mathrm{M}$ Oxalic acid & R.T. $(13 \mathrm{~d})$ & 16.7 & $0.93 \pm 0.03$ & $1.04 \pm 0.02$ \\
\hline $10 a$ & $1 \mathrm{M}$ Oxalic acid & $75^{\circ} \mathrm{C}(1 \mathrm{~d})+$ R.T. $(40 \mathrm{~d})$ & 17.8 & $0.90 \pm 0.03$ & \\
\hline
\end{tabular}

\section{R.T. : Room temperature}

(a)

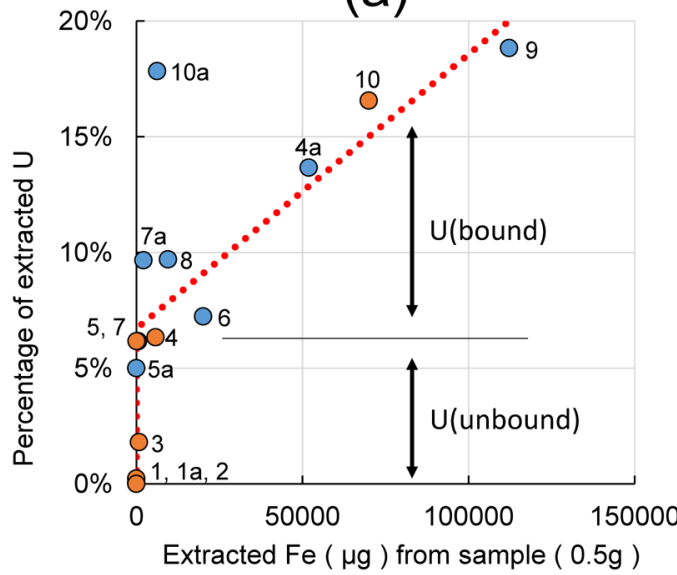

(b)

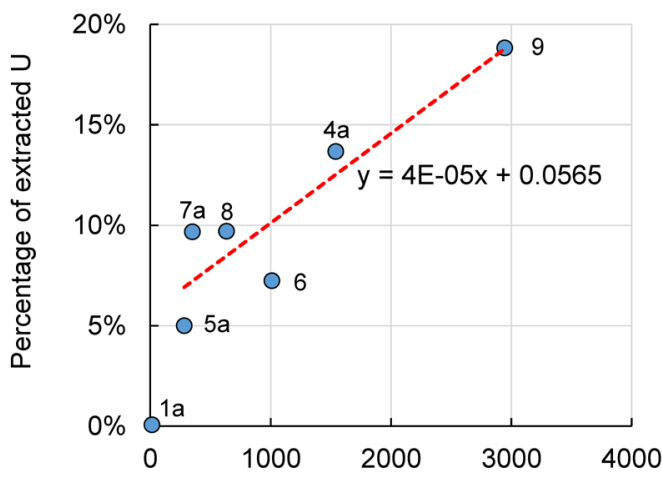

Total amount of extracted major ion $(\mu \mathrm{M})$ ( excluding $\mathrm{Na}$ )

Fig. 2 Correlation between $\mathrm{U}$ and (a) Fe, (b) sum of major elements extracted from weathered carbonatite sample (Sal-6) by various chemical reagents.

た。しかし，10aでは不溶性のシュウ酸鉄によ る実験誤差の可能性があるためこれを除くと, 相関係数は 0.86 となり, 更にFe溶出量の少な い $1,1 \mathrm{a}, 2,3$ を除くと 0.94 と改善された。すな わち, Fig. 2(a)の点線で示したように, 全Uの うち 7\%程度は Fe とは無関係に溶出し（図中の $\mathrm{U}$ (unbound)), その他は Fe成分と良い相関で 溶出している（図中のU（bound））と概ね見な
すことができる。Uの溶出割合で示したこの図 では，それぞれ近似式で

$\mathrm{U}$ (unbound) $=0.067$,

$\mathrm{U}$ (bound $)=\left(1.2 \times 10^{-6}\right) \times \mathrm{Fe}(\mu \mathrm{g})$,

溶出 $\mathrm{U}=\mathrm{U}$ (unbound) $+\mathrm{U}$ (bound)

$$
=0.067+\left(1.2 \times 10^{-6}\right) \times \mathrm{Fe}(\mu \mathrm{g})
$$


$\mathrm{Fe}$ の他に, $\mathrm{Al}, \mathrm{Ti}, \mathrm{Mn}, \mathrm{Ca}, \mathrm{Mg}, \mathrm{K}, \mathrm{P}$ などの $\mathrm{Na}$ 以外の主成分の総和モル数と溶出 $\mathrm{U}$ 量との関係 をFig. 2(b)に示した。10aを除き，また全体の デー夕数が異なるが，相関係数も 0.89 と $98 \%$ の信頼度で相関があると判断された。更に原点 付近のデータを除くと相関係数は 0.91 となり, Fig. 2 (a)の点線と同じ傾向で, 全Uのうち $6 \%$ 程度は主成分等とは無関係に溶出する様子を示 唆しており, Uの挙動に対する類似した作用が 推定された。

$\mathrm{U}$ (unbound) $=0.057$,

$\mathrm{U}$ (bound $)=\left(4.5 \times 10^{-5}\right) \times$ 主要総イオン $(\mu \mathrm{M})$,

溶出 $\mathrm{U}=\mathrm{U}$ (unbound) $+\mathrm{U}$ (bound)

$$
=0.057+\left(4.5 \times 10^{-5}\right) \times \text { 主要総イオン }(\mu \mathrm{M})
$$

$4 \cdot 4$ 溶出した $U$ の ${ }^{234} \mathrm{U} /{ }^{238} \mathrm{U}$ 放射能比

溶出したUの ${ }^{234} \mathrm{U} /{ }^{238} \mathrm{U}$ 放射能比は, Table 4 に示したようにいずれも1よりも小さかった。 ${ }^{234} \mathrm{U}$ は ${ }^{238} \mathrm{U}$ と比べて動きやすい核種であり, 抽 出液では ${ }^{234} \mathrm{U} /{ }^{238} \mathrm{U}$ 放射能比は 1 よりも大きく なる, と従来から考えられ, 抽出液で源岩中 の放射能比よりも高くなることが報告されて いる ${ }^{16,17)}$ 。特に 64.3 というかなり高い放射能 比がOklo鉱石からの酸抽出により得られてい る ${ }^{18)}$ 。中国のボーキサイト堆積物からの酸抽 出液でも, ${ }^{234} \mathrm{U} /{ }^{238} \mathrm{U}$ 放射能比は 1 よりも大きく なっていた ${ }^{13)}$ 。しかし，本研究結果ではそれ

(a)

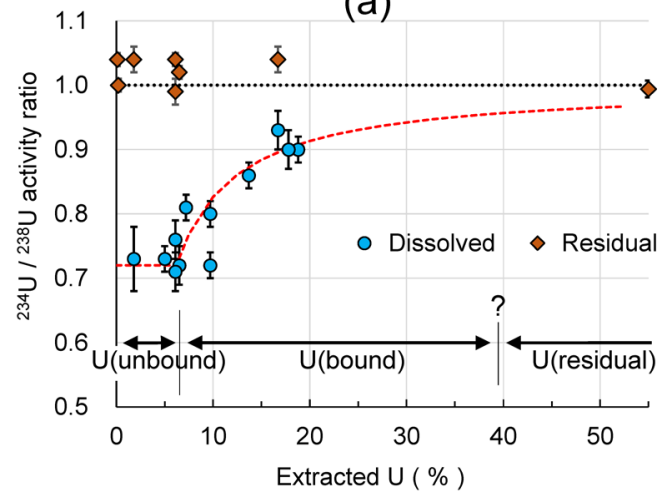

とは反対の結果となっており，こうした報告は これまでにほとんどなされていない。

Fig. 3 (a)に溶出 $U$ 量と ${ }^{234} U{ }^{238} U$ 放射能比の関 係を示したが，抽出作用が弱くUの溶出量が少 ない場合には放射能比が小さく $\left({ }^{238} \mathrm{U}>{ }^{234} \mathrm{U}\right)$, 溶出量が増えるに従って放射能比が 1 に近づい ており， ${ }^{238} \mathrm{U}$ の方が弱い作用で溶出しやすく ${ }^{234} \mathrm{U}$ の方がより強く結合している，という傾向 となった。また，主成分の $\mathrm{Fe}$ の溶出量との関 係を Fig. 3(b) に示したが, Fig. 3(a) と同様な傾 向を示している。このような結果の説明には, ${ }^{238} \mathrm{U}$ に比べて ${ }^{234} \mathrm{U}$ が結晶格子に強く結合してい るモデルが必要であるが, そうしたモデルは考 えにくい。そうではなく, 堆積物中のUの存在 状態には3 種類の形態が有り，その一つは $\mathrm{Fe}$ どに影響されずに溶出するU (unbound)，二つ 目はFeなどと共に溶出するU (bound), そし てもう一つが難溶性のU（residual）と考えるの が妥当である。なお, 分別溶解法 ${ }^{19)}$ ではイオ ン交換性のフラクションを酢酸アンモニウム 溶液などによる抽出フラクションとしている が，本研究ではほとんど抽出されなかったため (Table 4のNo. 2), U (unbound) はイオン交換 性フラクションとは異なると考えられる。

ここで, Eq. (1)で示したU (unbound) とU （bound）がそれぞれ異なる ${ }^{234} \mathrm{U} /{ }^{238} \mathrm{U}$ 放射能比 （AR）を持つと仮定し，それぞれを添字

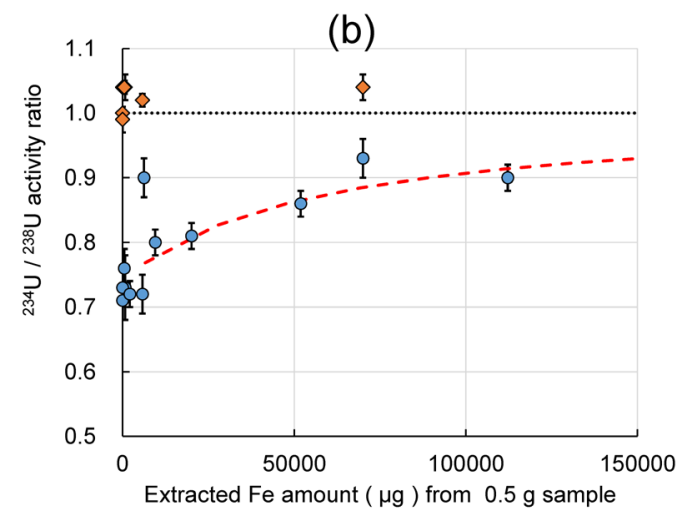

Fig. 3 Correlation between ${ }^{234} U^{238} U$ activity ratio and (a) $U$, (b) Fe extracted from weathered carbonatite sample (Sal-6) by various chemical reagents. 
区別すると, 抽出液 ${ }_{\text {sol }}$ と略記) では,

$$
\begin{aligned}
\mathrm{AR}_{\mathrm{u}} & ={ }^{234} \mathrm{U}_{\mathrm{u}} /{ }^{238} \mathrm{U}_{\mathrm{u}}, \mathrm{AR}_{\mathrm{b}}={ }^{234} \mathrm{U}_{\mathrm{b}} /{ }^{238} \mathrm{U}_{\mathrm{b}} \\
{ }^{234} \mathrm{U}_{\mathrm{sol}} & ={ }^{234} \mathrm{U}_{\mathrm{u}}+{ }^{234} \mathrm{U}_{\mathrm{b}},{ }^{238} \mathrm{U}_{\text {sol }}={ }^{238} \mathrm{U}_{\mathrm{u}}+{ }^{238} \mathrm{U}_{\mathrm{b}}(4) \\
\mathrm{AR}_{\mathrm{sol}} & ={ }^{234} \mathrm{U}_{\text {sol }}{ }^{238} \mathrm{U}_{\text {sol }} \\
& =\left(\mathrm{AR}_{\mathrm{u}} \times{ }^{238} \mathrm{U}_{\mathrm{u}}+\mathrm{AR}_{\mathrm{b}} \times{ }^{238} \mathrm{U}_{\mathrm{b}}\right) /{ }^{238} \mathrm{U}_{\text {sol }} \\
& =\left[\mathrm{AR}_{\mathrm{u}} \times{ }^{238} \mathrm{U}_{\mathrm{u}}+\mathrm{AR}_{\mathrm{b}} \times\left({ }^{238} \mathrm{U}_{\mathrm{sol}}-{ }^{238} \mathrm{U}_{\mathrm{u}}\right)\right] /{ }^{238} \mathrm{U}_{\text {sol }} \\
& =\mathrm{AR}_{\mathrm{b}}-\left(\mathrm{AR}_{\mathrm{b}}-\mathrm{AR}_{\mathrm{u}}\right) \times{ }^{238} \mathrm{U}_{\mathrm{u}} /{ }^{238} \mathrm{U}_{\mathrm{sol}}
\end{aligned}
$$

となる。このEq. (5)は, 溶出したUの ${ }^{234} \mathrm{U} /{ }^{238} \mathrm{U}$ 放射能比が ${ }^{238} \mathrm{U}_{\mathrm{u}}{ }^{238} \mathrm{U}_{\mathrm{sol}}$ に対して一次関数（但 し, $\left.{ }^{238} \mathrm{U}_{\mathrm{sol}} \mathrm{P}^{238} \mathrm{U}_{\mathrm{u}}\right)$ となることを示している。

$\mathrm{AR}_{\mathrm{u}}$ は，Table 4およびFig. 3(b)における溶 出 $\mathrm{Fe}$ 量の少ないときの ( $\mathrm{U}$ (unbound)) の ${ }^{234} \mathrm{U} /{ }^{238} \mathrm{U}$ 放射能比 $0.71-0.73$ の平均から, 約 0.72 と推定される。また, ${ }^{238} \mathrm{U}_{\mathrm{u}}$ (U (unbound)) は, Fig. 2(a)，（b)及びEq. (1)，(2)から0.0570.067（平均 0.062）と推定される。これらの 值を用いてEq. (5)の関係から最小自乗法を用 いて $\mathrm{AR}_{\mathrm{b}}$ を求めたところ, Fig. 4に示した直 線（Eq. (5)) の傾き $\left(-\left(\mathrm{AR}_{\mathrm{b}}-\mathrm{AR}_{\mathrm{u}}\right)\right)$ が-0.28 であることから $\mathrm{AR}_{\mathrm{b}}=1.00$, 切片 $\left(\mathrm{AR}_{\mathrm{b}}\right)$ から $\mathrm{AR}_{\mathrm{b}}=0.99$ となり, $\mathrm{Fe}$ などの主要成分の溶出に 伴う $U$ (bound) ${ }^{234} U /{ }^{238} U$ 放射能比は 1 前後と 推定される。

残さ部分の $U(U($ residual $))$ の ${ }^{234} U /{ }^{238} U$ 放 射能比が 0.99-1.04（平均で約 1.02）であるこ と（Table 4 およびFig. 3参照）とバルクでの ${ }^{234} \mathrm{U} /{ }^{238} \mathrm{U}$ 放射能比がほぼ1であることから，こ れらの結果は測定誤差を考えるといずれも妥当 な結果である。

以上のことから, 堆積物中のUの存在状態 には ${ }^{234} \mathrm{U} /{ }^{238} \mathrm{U}$ 放射能比が 0.72 程度で $\mathrm{Fe}$ などに 影響されずに溶出するU (unbound)，放射能比 が1程度でFeなどと共に溶出するU（bound）, そして放射能比が1.02前後で難溶性のU（residual）があり，全体としては ${ }^{234} \mathrm{U} /{ }^{238} \mathrm{U}$ 放射能比 が1に近いものとなっていると推定される。残 さフラクションで放射能比が1よりも大きいの は, アルファ反跳による効果で難溶性粒子に

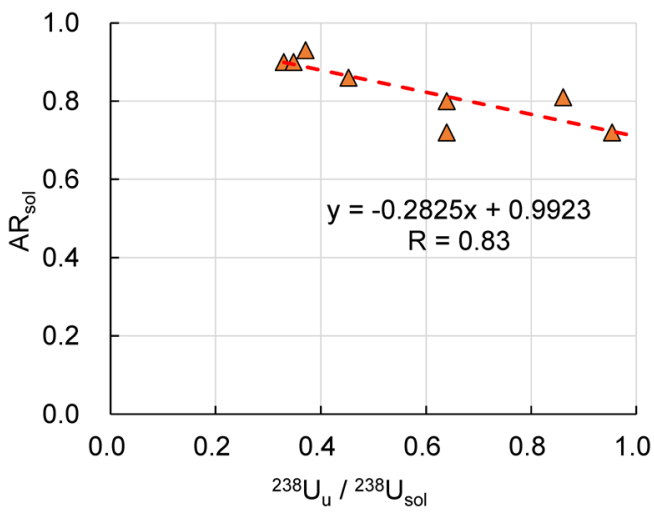

Fig. 4 Regression lines for Eq. (5) assuming $\mathrm{AR}_{\mathrm{u}}=0.72$ and ${ }^{238} \mathrm{U}_{\mathrm{u}}=0.062$.

${ }^{234} \mathrm{U}$ が増えているためと考えられる。Lawson et al（1986）もラテライト土壤中のUを幾つかの 相に分別し，不溶解相で娘核種が濃集してい ることを報告している ${ }^{20)}$ 。一方，最初に溶出 するUの放射能比が 1 よりも小さくなるのは, ${ }^{238} \mathrm{U}$ が多く溶け出すのではなく, 風化がかなり 進んで ${ }^{234} \mathrm{U}$ が減少して ${ }^{234} \mathrm{U} /{ }^{238} \mathrm{U}$ 放射能比が 0.72 程度となった溶けやすいUフラクションがU全 体の 6-7\%程度有り，それが最初に溶出したた めと考えられる。

\section{5. まとめ}

ブラジルのサリトレ（Salitre）鉱床から得た 風化カーボナタイト試料におけるUの特徵を明 らかにするために, $\mathrm{U}$ 濃度, ${ }^{234} \mathrm{U} /{ }^{238} \mathrm{U}$ 放射能比 や溶出特性などについて検討した。U濃度は, 20-30 ppm 程度であり, 通常の土壤や平均地凯 存在度より高かった。 ${ }^{234} \mathrm{U} /{ }^{238} \mathrm{U}$ 放射能比はほと んど1に近く，マクロな視点で見た場合には， ほぼ放射平衡と見なされた。

しかし詳細に見ると，堆積物中のUには ${ }^{234} \mathrm{U} /{ }^{238} \mathrm{U}$ 放射能比が約 $0.72 て ゙ F e$ などに影響さ れずに溶出するフラクション, 放射能比が 1 程 度で $\mathrm{Fe}$ などと共に溶出するフラクション，そ して放射能比が約 $1.02 て ゙$ 難溶性のフラクショ ンがあり，全体として ${ }^{234} \mathrm{U} /{ }^{238} \mathrm{U}$ 放射能比が 1 と なっていることが抽出実験から示唆された。 
溶出した $U$ の ${ }^{234} \mathrm{U} /{ }^{238} \mathrm{U}$ 放射能比が 1 よりも大 きいという報告は多いが，1よりも小さいとい う報告はこれまでほとんどなかった。この現象 は ${ }^{238} \mathrm{U}$ が多く溶け出すのではなく, 風化がかな り進んで ${ }^{234} \mathrm{U}$ がかなり減少して ${ }^{234} \mathrm{U} /{ }^{238} \mathrm{U}$ 放射能 比が 0.72 程度となった溶けやすいUが一部に残 存し，それが溶出してくるためと考えられた。

\section{謝 辞}

本研究を行うに当たり, 地質調査所当時の 安藤 厚氏, 藤貫 正氏, (故)後藤隼次氏, 今 井 登氏, 神谷雅晴氏など, 関係各位から研究 試料の提供やご指導・ご協力をいただいた。ま た, 匿名の 2 名の査読者からは貴重なコメント をいただいた。ここに記して感謝申し上げる。

\section{文献}

1) 立見辰雄, カーボナタイトおよびアルカ リ岩複合岩体に伴う鉱床, 地学雑誌, 74, 13-33 (1965)

2) 武内寿久祢, カーボナタイト鉱床 (II) (ヨーロッ パ，ソ連その他の地域のカーボナタイト), 鉱 山地質, 23,437-451（1973）

3）神谷雅晴, ブラジルの地質とカーボナタイト鉱 床(1)，地質ニュース，362,24-33（1984）

4) 金井 豊, ブラジル産風化カーボナタイト試料 中のウラン定量法の比較検討, 地質調査研究報 告, 66, 159-167 (2015)

5) 渡辺 寧, レアメタルテキスト：(1) 希土類, 資源地質， 60, 103-122（2010）

6) MITI, Research on mineral deposits associated with carbonatite in Brazil, ITIT Projects No. 8316, International Research and Development Cooperation Division, Agency of Industrial Science and Technology, MITI (1987)

7) Fujii, K., Preface; Special Issue for overseas geology and mineral resources (IV): Research on mineral deposits associated with carbonatite in Brazil, Bull. Geol. Surv. Japan, 41, 576 (1990)
8) Kamitani, M. and Hirano, H., Araxa carbonatite deposit and its lateritization, Bull. Geol. Surv. Japan, 41, 595-604 (1990)

9) Hirano, H., Kamitani, M., Sato, T. and Sudo, S., Niobium mineralization of Catalao I carbonatite complex, Goias, Brazil, Bull. Geol. Surv. Japan, 41, 577-594 (1984)

10) Kanai, Y., Determination of ${ }^{234} U{ }^{238} U$ activity ratios in geological reference materials by alpha spectrometry, Radioisotopes, 35, 601-604 (1986)

11）神谷雅晴, 平野英雄, ブラジルの地質とカーボナ タイト鉱床 (2)，地質ニュース，372,6-16（1985）

12) Fujinuki, T., Determination of $\mathrm{Nb}$ and $\mathrm{Ta}$ in weathering soils from Brazilian carbonatite complexes, Bull. Geol. Surv. Japan, 41, 627-629 (1990)

13) Kanai, Y., Uranium distribution and ${ }^{234} U /{ }^{238} U$ activity ratios in a sedimentary bauxite deposit, from Yangwa mine, China, and its implication for sedimentation process, Geochem. J., 26, 207-218 (1992)

14) Kigoshi, K., Alpha-recoil thorium-234: Dissolution into water and the uranium-234/uranium-238 disequilibrium in nature, Science, 173, 47-48 (1971)

15) Fleischer, R. L., Isotopic disequilibrium of uranium: Alpha-recil damage and preferential solution effects, Science, 207, 979-981 (1980)

16) Sheng, Z. Z., Fractionation of thorium and uranium isotopes in the acid leaching experiments on monazite, J. Radioanal. Nucl. Chem., 134, 293-298 (1989)

17) Morimoto, T., Banba, S., Ishikawa, K., Shinoda, Y. and Hashimoto, T., Alpha-Recoil nuclides in acid leaching experiments on radioactive ores, Radioisotopes, 52, 269-276 (2003)

18) Sheng, Z. Z. and Kuroda, P. K., The $\alpha$-recoil effects of uranium in the Oklo reactor, Nature, 312, 535-536 (1984)

19）金井 豊，第2編第 12 章第3 節分別溶解法によ る堆積物の物質解明, pp. 802-812, 土の環境圈 (岩田進午・喜田大三監修), 1388 pp., フジ・テ クノシステム, 東京 (1997)

20) Lowson, R. T., Short, S. A., Davey, B. G. and Gray, D. J., ${ }^{234} \mathrm{U} /{ }^{238} \mathrm{U}$ and ${ }^{230} \mathrm{Th} /{ }^{234} \mathrm{U}$ activity ratios in mineral phases of a lateritic weathered zone, Geochim. Cosmochim. Acta, 50, 1697-1702 (1986) 


\title{
Abstract
}

\section{Characterization of Uranium in Weathered Carbonatite from the Salitre Mine, Brazil}

\author{
Yutaka KANAI $^{\dagger}$ \\ Geological Survey of Japan, National Institute of Advanced Industrial Science and Technology (AIST) \\ 1-1-1 Higashi, Tsukuba-shi, Ibaraki Pref. 305-8567, Japan \\ $U$ contents of weathered carbonatites from the Salitre mine, Brazil, were $20-30$ ppm and their ${ }^{234} U{ }^{238} U$ \\ activity ratios were nearly 1, suggesting their equilibria. The easily soluble, the Fe-bound, and the insoluble \\ fractions with activity ratios of $0.72,1$, and 1.02, respectively, were assumed. Elution of $U$ with activity ratio $<1$ \\ was ascribed to the extraction of highly depleted $U$ by strong weathering.
}

(Received August 20, 2015)

(Accepted November 9, 2015) 